\title{
A Clinico Histopathological Study of Childhood Leprosy
}

\author{
*Dr.T.V.Narsimha Rao ${ }^{1}$, Dr.G.Leelavathi ${ }^{2}$, Dr.G.Purnima ${ }^{3}$ \\ (Dept. of DVL, Siddhartha medical college, Vijayawada, Andhra Pradesh, India.). \\ *Corresponding author: Dr.G.Leelavathi
}

\begin{abstract}
:
Background: Leprosy is one of the oldest diseases known to mankind and is still associated with stigma. A high child proportion signifies active and recent transmission of the disease.

Aim: To know the proportion of children in newly detected leprosy patients and their clinico histopathological categorisation.

Methodology: This was a retrospective analysis of all leprosy patients less than 16 years of age registered at the Leprosy Clinic of GGH, Vijayawada from January2015-June2016.

Results: Proportion of children among newly diagnosed leprosy patients was $9.2 \%$. Majority of patients belonged to age group of 13 to 16 years(48\%), with male preponderance. $24 \%$ patients gave family history of leprosy. $40 \%$ of patients belonged to PB type, $60 \%$ MB type. Slit skin smear was positive in $20 \%$. According to clinical characteristics, majority of patients belonged to BT(52\%) followed by TT(32\%). According to histopathological characteristics majority of patients belonged to BT(48\%) followed by TT(36\%).Clinico Histopathological correlation in LL Hansen's is 100\%, in BT 76\%.Type I reaction occurred in 2 patients( $8 \%)$.Deformities were observed in $8 \%$ patients.

Conclusion: Despite statistical elimination of leprosy, childhood leprosy still remains a public health problem. Early detection, treatment and contact tracing are important for reducing the burden of leprosy in the community.
\end{abstract}

Keywords: Childhood leprosy, Clinico histopathological correlation.

\section{Introduction}

Leprosy is one of the oldest diseases known to mankind that is almost 3000 years ago and is still associated with stigma. The causative pathogen Mycobacterium leprae, was first described in 1873 by Gerhard Henrik Armaeur Hansen.

India achieved elimination of leprosy at national level in December 2005, although the prevalence far exceeded the elimination level in many states. India still remains as the largest home for leprosy with $48.54 \%$ of world"s leprosy patients from India in the year 2012-2013. ${ }^{[1]} 9.93 \%$ of the new leprosy cases detected during 2012-2013 in India were children ${ }^{[2]}$ a stratum that accounts for 37\% of the total population (Dayal, 1995). Children presenting late, with stigmatizing deformity, indicates inadequate early case detection activities as well as reluctance on the part of their parents to come forward to access the health system. ${ }^{[3]}$

The magnitude of childhood leprosy is regarded as one of the most sensitive performance indicators of the National leprosy elimination programme (NLEP) (WHO, 2005). There are very few studies on childhood leprosy, hence we made an attempt to study incidence and clinical characteristics of childhood leprosy.

\section{Aim}

To know the proportion of children in newly detected leprosy patients and their clinico histopathological categorisation

\section{Patients And Methods}

This was a retrospective analysis of all leprosy patients less than 16 years of age registered at the Leprosy Clinic of GGH, Vijayawada from January2015-June2016.

The children were examined clinically and classified as paucibacillary (PB) or multi bacillary (MB) as per WHO classification. A slit skin smear (SSS) was taken, stained by Ziehl Neelsen stain and graded as per Ridley's bacteriological index (BI). ${ }^{[4]}$ A lesional skin biopsy was obtained under aseptic conditions following verbal consent from the patient (minor) and written informed consent from the guardian.

\section{Observations And Results}

The following observations were made in a prospective study which included children aged between $0-16$ yrs, diagnosed with leprosy in a period of 18 months from January 2015 - June 2016. 


\section{Proportion of children}

Table: 1

\begin{tabular}{|l|l|l|}
\hline & No of patients & Percentage $(\%)$ \\
\hline Children & 25 & 9.2 \\
\hline Adults & 246 & 90.8 \\
\hline Total & 271 & 100 \\
\hline
\end{tabular}

Proportion of children among newly diagnosed leprosy patients is $9.2 \%$ (i.e 25 were children among 271 new leprosy patients).

\section{Age wise distribution $(n=25)$}

Table: 2

\begin{tabular}{|l|l|}
\hline Age (years) & No of patients \\
\hline $0-4$ & NIL \\
\hline $5-8$ & $05(20 \%)$ \\
\hline $9-12$ & $08(32 \%)$ \\
\hline $13-16$ & $12(48 \%)$ \\
\hline Total & 25 \\
\hline
\end{tabular}

Majority of patients belonged to age group of 13-16 yrs(48\%), followed by $9-12 \mathrm{yrs}(32 \%), 5-8 \mathrm{yrs}(20 \%)$.

3. Sex wise distributions $(\mathrm{n}=\mathbf{2 5})$

Table: 3

\begin{tabular}{|l|l|l|}
\hline Sex & No. of patients & Percentage \\
\hline Male & 14 & $56 \%$ \\
\hline Female & 11 & $44 \%$ \\
\hline Total & 25 & $100 \%$ \\
\hline
\end{tabular}

Majority of the patients were males(56\%).

4. Distribution according to family history $(n=25)$

Table: 4

\begin{tabular}{|l|l|l|}
\hline Family history of Leprosy & No. of patients & Percentage(\%) \\
\hline Positive & 06 & 24 \\
\hline Negative & 19 & 76 \\
\hline Total & 25 & 100 \\
\hline
\end{tabular}

Out of 25 patients, 6 patients gave family history of leprosy.

\section{Distribution according to WHO classification $(n=25)$}

Table: 5

\begin{tabular}{|l|l|l|}
\hline WHO classification & No.of patients & Percentage(\%) \\
\hline PB & 10 & 40 \\
\hline MB & 15 & 60 \\
\hline Total & 25 & 100 \\
\hline
\end{tabular}

According to WHO classification, $40 \%$ of patients belonged to PB type and $60 \%$ MB type.

\section{Distribution of subjects by AFB status $(n=25)$}

Table: 6

\begin{tabular}{|l|l|l|}
\hline AFB & No. of patients & Percentage $(\%)$ \\
\hline Positive & 05 & 20 \\
\hline Negative & 20 & 80 \\
\hline Total & 25 & 100 \\
\hline
\end{tabular}

Demonstration of acid fast bacilli by slit skin smear positive in $20 \%$, negative in $80 \%$ of patients.

7. Distribution of subjects by Clinical types $(n=25)$

Table: 7

\begin{tabular}{|c|c|c|}
\hline Clinical Type of Leprosy & No. of patients & Percentage $(\%)$ \\
\hline TT & 8 & $32 \%$ \\
\hline BT & 13 & $52 \%$ \\
\hline BB & Nil & Nil \\
\hline
\end{tabular}


A Clinico Histopathological Study of Childhood Leprosy

\begin{tabular}{|c|c|c|}
\hline BL & 3 & $12 \%$ \\
\hline LL & 1 & $4 \%$ \\
\hline IL & Nil & Nil \\
\hline Total & 25 & $100 \%$ \\
\hline
\end{tabular}

According to clinical characteristics majority of the patients belonged to BT (52\%), followed by TT(32\%), BL(12\%), LL(4\%).

8. Distribution according to Histopathological types $(n=25)$

Table: 8

\begin{tabular}{|c|c|c|}
\hline Histopathological Type & No. of patients & Percentage(\%) \\
\hline TT & 9 & $36 \%$ \\
\hline BT & 12 & Nil \\
\hline BB & Nil & $4 \%$ \\
\hline BL & 1 & $4 \%$ \\
\hline LL & 1 & $8 \%$ \\
\hline IL & 2 & $100 \%$ \\
\hline Total & 25 & \\
\hline
\end{tabular}

According to histopathological characteristics, majority of patients belonged to BT(48\%), followed by $\mathrm{TT}(36 \%), \operatorname{IL}(8 \%), \mathrm{BL}(4 \%), \mathrm{LL}(4 \%)$.

\section{Clinico histopathological correlation $(n=25)$}

Table: 9

\begin{tabular}{|c|c|c|c|c|c|c|c|c|}
\hline $\begin{array}{c}\text { Clinical } \\
\text { Diagnosis }\end{array}$ & \multicolumn{7}{|c|}{ Histopathological Diagnosis } & \multirow{2}{*}{ Aggregate(\%) } \\
\cline { 1 - 7 } Type & No & 9 & BT & BB & BL & LL & IL & \multirow{2}{*}{} \\
\hline & 8 & 6 & & 0 & 1 & 1 & 2 & $72 \%$ \\
\hline TT & 13 & 3 & 10 & & & & & $76 \%$ \\
\hline BT & 0 & & & & & & & \\
\hline BB & 3 & & 2 & & 1 & & & $33 \%$ \\
\hline BL & 1 & & & & & 1 & & $100 \%$ \\
\hline LL & 0 & & & & & & & \\
\hline IL & & & & & & & \\
\hline
\end{tabular}

Clinico histopathological correlation in LL leprosy was 100\%, in BT 76\%, in TT 72\%, in BL $33 \%$

10. Overall parity between clinical and histopathological types $(n=25)$

Table 10:

\begin{tabular}{|c|c|c|}
\hline $\begin{array}{c}\text { Overall parity between clinical \& } \\
\text { histopathological type }\end{array}$ & No. of patients & Percentage(\%) \\
\hline Parity & 18 & $72 \%$ \\
\hline Disparity & 7 & $28 \%$ \\
\hline Total & 25 & $100 \%$ \\
\hline
\end{tabular}

Clinico histopathological correlation observed in $72 \%$ and disparity seen in $28 \%$ of patients.

\section{Distribution of subjects by reaction $(n=25)$}

Table: 11

\begin{tabular}{|c|c|c|}
\hline Reaction & No. of patients & Percentage(\%) \\
\hline Type I & 2 & $8 \%$ \\
\hline Type II & Nil & Nil \\
\hline Negative & 23 & $92 \%$ \\
\hline Total & 25 & $100 \%$ \\
\hline
\end{tabular}

- Reactional episodes in the form of type 1 reaction occurred in 2 patients (8\%).

- One patient of BT leprosy presented with neuritis.

- One patient of TT leprosy developed neuritis during treatment. 
A Clinico Histopathological Study of Childhood Leprosy

12. Distribution of subjects by deformity $(n=25)$

Table: 12

\begin{tabular}{|c|c|c|}
\hline Deformity & No. of patients & Percentage $(\%)$ \\
\hline Present & 2 & $8 \%$ \\
\hline Absent & 23 & $92 \%$ \\
\hline Total & 25 & $100 \%$ \\
\hline
\end{tabular}

\section{Deformity was observed in two patients.}

One child of LL leprosy (BI-5+)with HIV positive, presented with claw hand with secondary deformities like joint stiffness, volar skin contractures in hands, ulcers and shortening of digits.

Other child of BL leprosy with bacillary index 4+ presented with ulnar claw hand at the time of diagnosis.

Fig: 1 Borderline Tuberculoid Leprosy

Fig: 2 Tuberculoid Leprosy

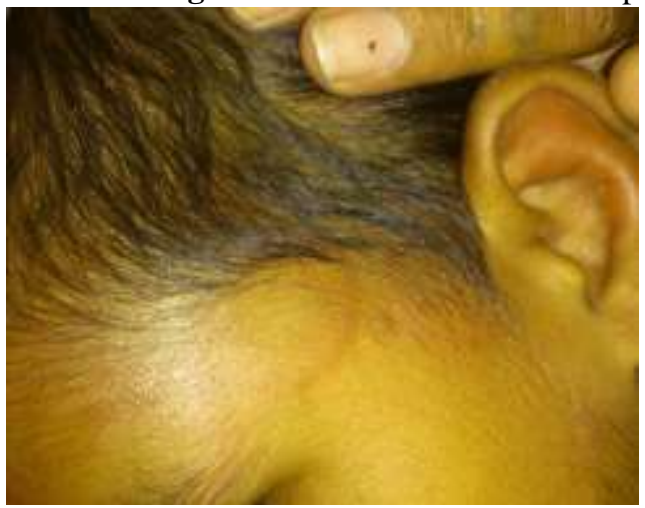

Fig: 3 Borderline Tuberculoid Leprosy

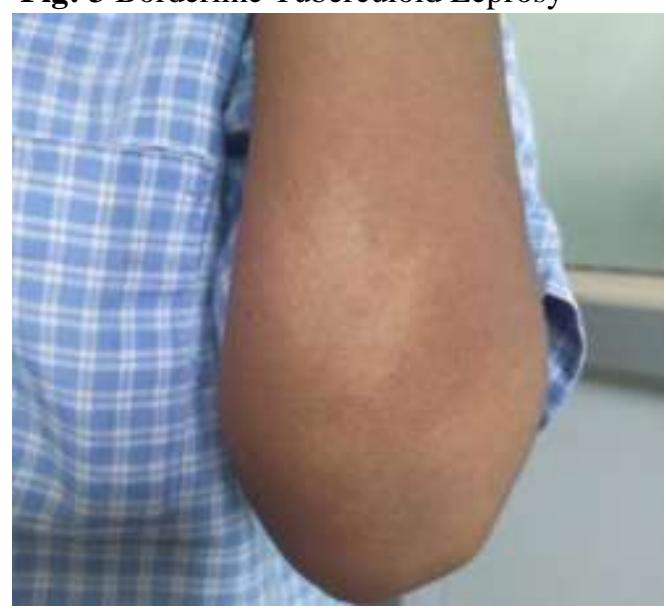

Fig: 5 Tuberculoid Leprosy with type 1 reaction

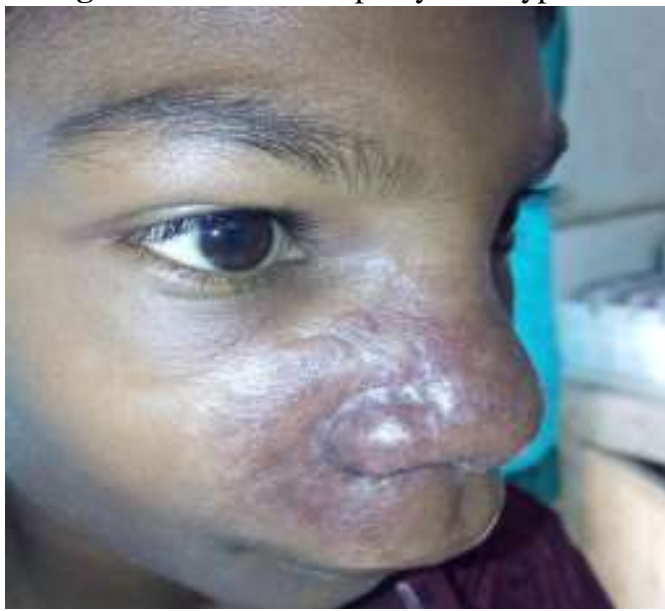

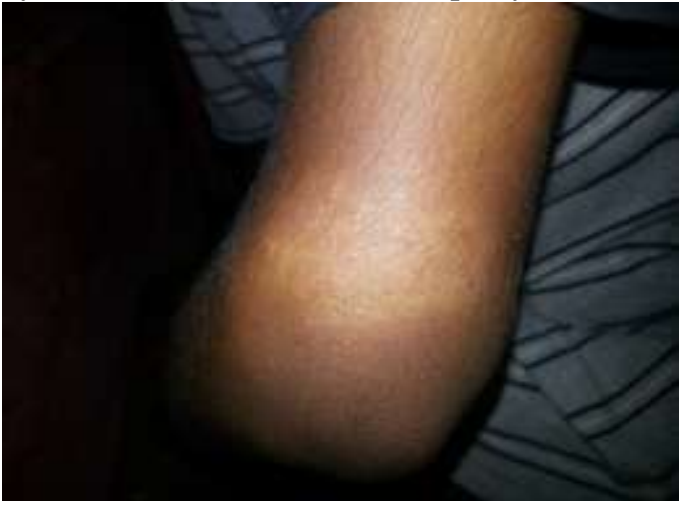

Fig: 4 Borderline Lepromatous Leprosy

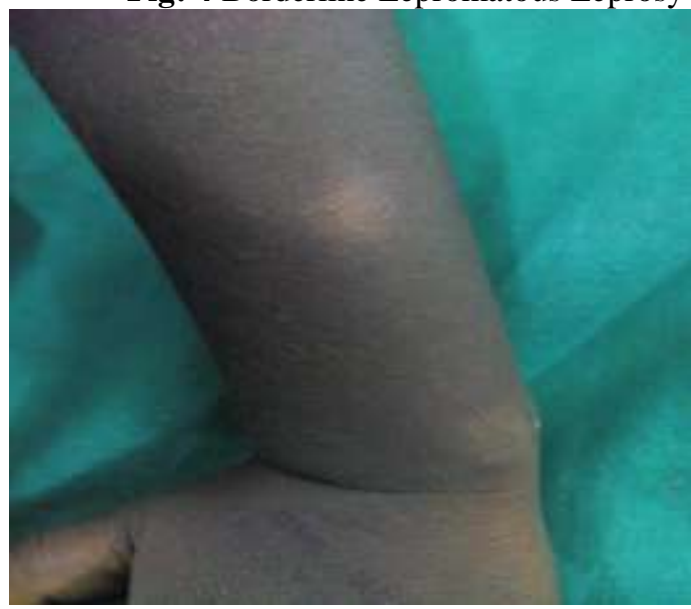

Fig: 6 Ulnar claw hand

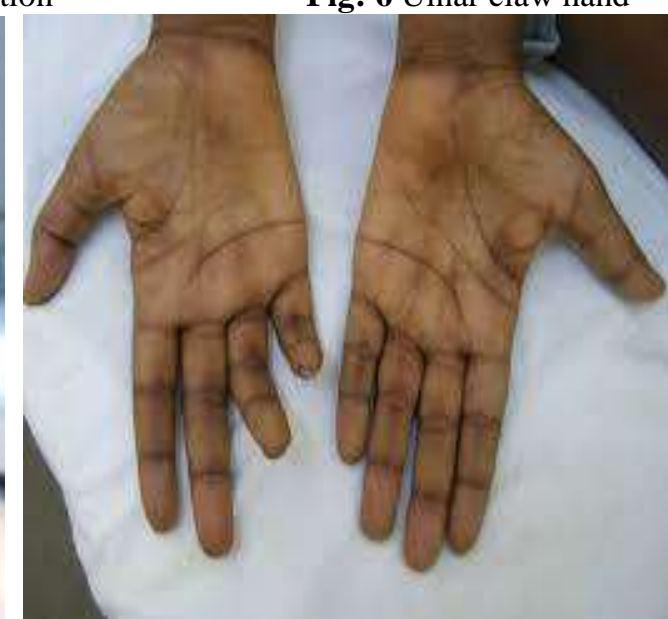


Fig: 7 Lepromatous Leprosy with absorption of digits

Fig: 8 SSS showing AFB
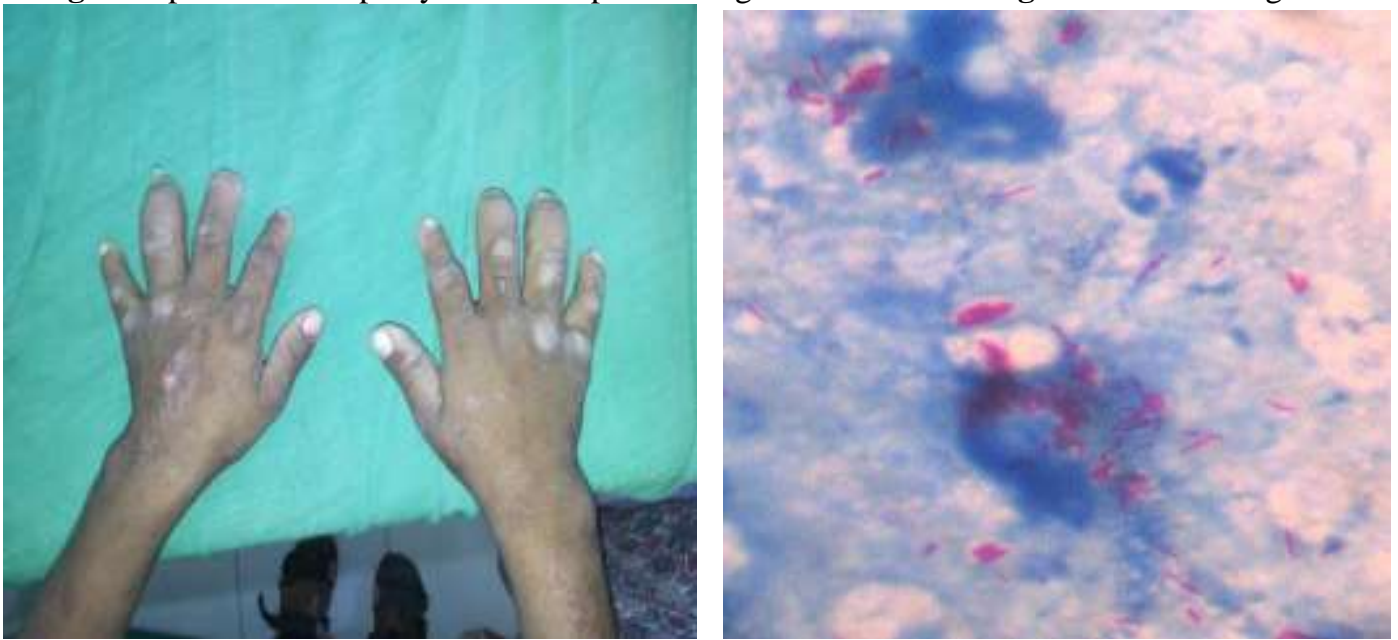

Fig: 9 Indeterminate leprosy (H\&E stain X 100)

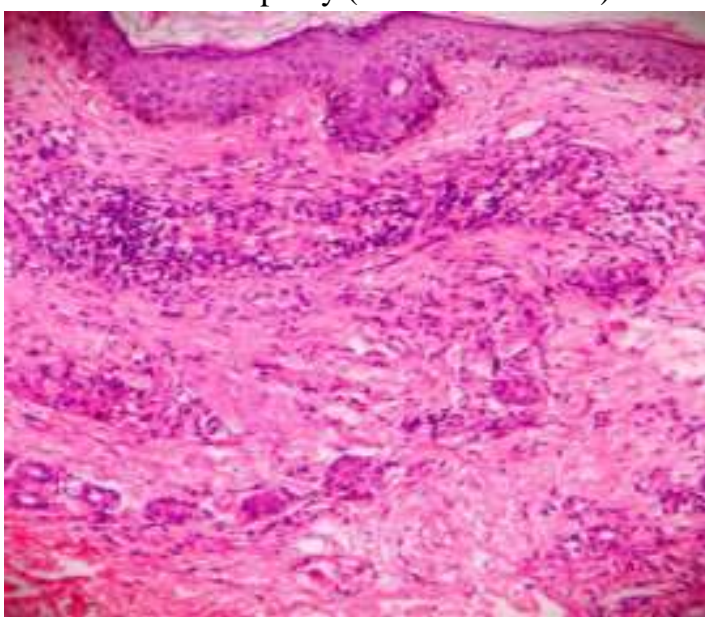

Fig: 10 Tuberculoid leprosy section(H\&E stain X100)

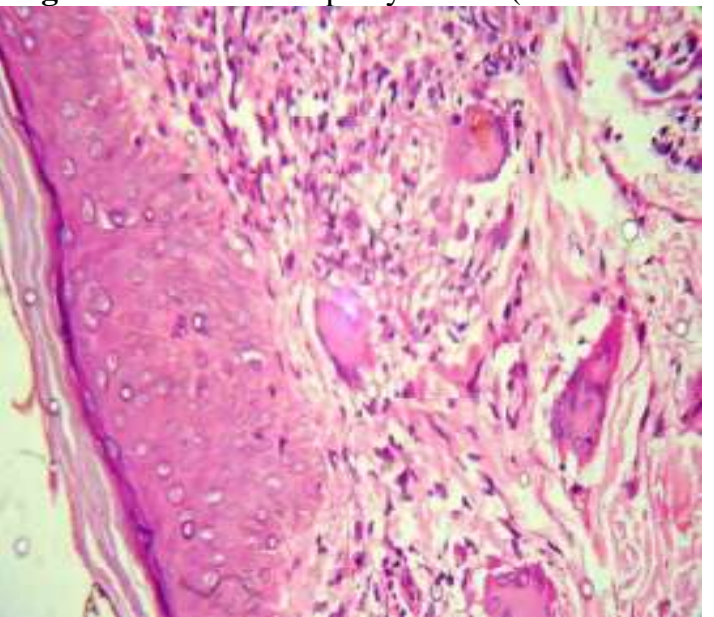

Fig: 11 Borderline Tuberculoid Leprosy(H\&EstainX100) Fig:12 Lepromatous leprosy (H\&E stain X100)
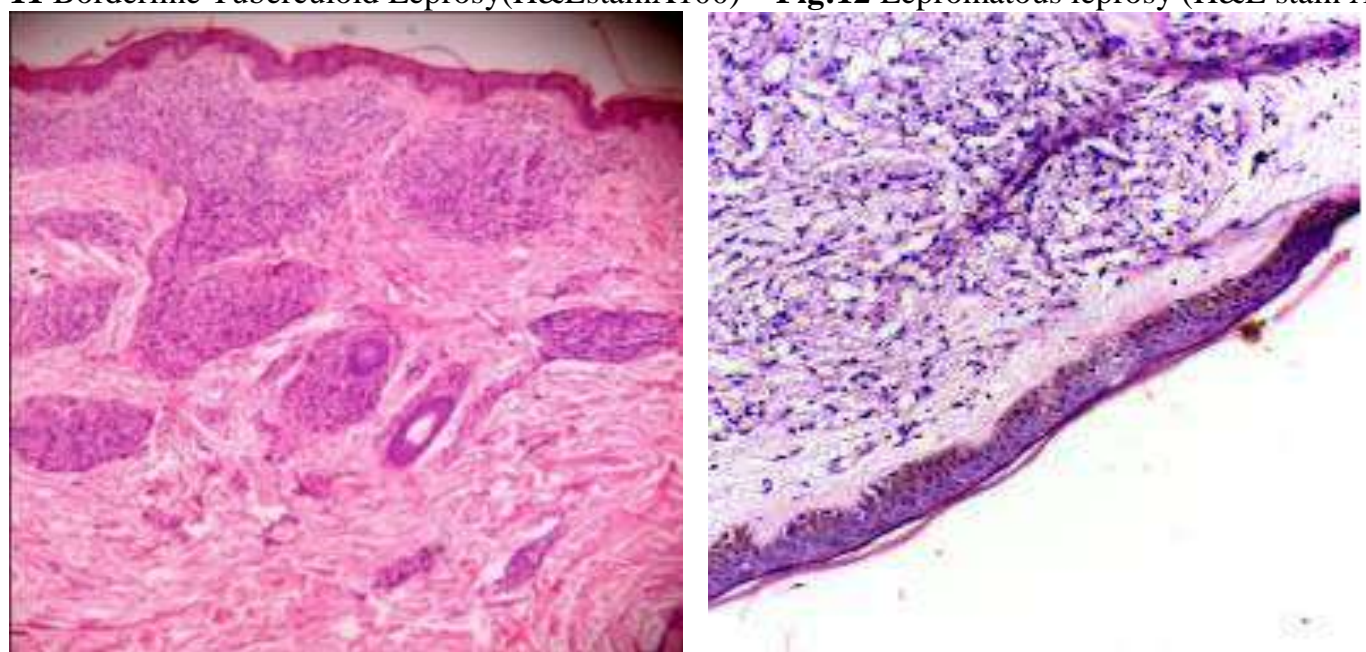

\section{Discussion}

Leprosy is a slowly progressive, chronic infectious disease caused by the bacillus Mycobacterium leprae.

The proportion of children among newly detected cases of leprosy is a strong indicator of disease transmission in the community. Globally, this ratio has shown a considerable variation. As per World Health Organisation (WHO) estimates in beginning of 2009, child proportion has ranged from $0.52 \%$ in Argentina to $10 \cdot 14 \%$ in 
India to as high as $39.50 \%$ in the Federated States of Micronesia. ${ }^{[5]}$

Childhood proportion:

The child proportion of $9.2 \%$ noted in our study was comparable to Singal \& Pandhi et al (9.6\%) studies but much higher than Burman et al (4.5\%) studies and Sachdevan et al studies $(5.1 \%)$.

Higher proportion in our study indicates hidden cases as well as continuing active transmission in the community. As the transmission declines, the disease is seen in older age groups. Children are more susceptible than adults with possible intra familial contact. ${ }^{[6]}$

Leprosy in children forms an important link in the natural evolution and the epidemic profile of the disease. It allows the identification of index case. With the declaration of leprosy elimination, there is a waning of awareness of leprosy among the health care workers and the general population which may be the cause of increased incidence of leprosy in children. ${ }^{[3]}$

\section{Age distribution:}

In our study, most of the patients were above 9yrs ( $9-12$ yrs : $32 \% ; 13-16$ yrs : 48\%).

According to Singal et al ${ }^{[7]}$, majority of childhood leprosy patients are above $11 \mathrm{yrs}(70.3 \%)$.

According to Chaitra et al, ${ }^{[8]} 75 \%$ of childhood patients were above $11 \mathrm{yrs}$.

Sachdeva et al also found majority of childhood leprosy patients above $11 \mathrm{yrs}$.

This may be due to relatively long incubation period of leprosy and also due to chance of misdiagnosing and delayed diagnosis of indeterminate skin patches in the initial stages. ${ }^{[9]}$

\section{Sex distribution:}

In our study, 14 (56\%) patients were males and 11 (44\%) patients were females.

According to Singal et al, Chaitra et al \& Sachdeva et al there is male preponderance.

Male preponderance in our study is consistent with other studies. This may be due to greater activity and increased opportunities for contact in males and neglect of female child.

\section{Family history :}

In this study, $\mathrm{H} / \mathrm{O}$ contact was present in $24 \%$ of patients.

In Singal et al study, $\mathrm{H} / \mathrm{O}$ contact was present in $14.5 \%$ of patients.

In Chaitra et al study, $\mathrm{H} / \mathrm{O}$ contact was present in $58.33 \%$ of patients.

In Sachdeva et al, $\mathrm{H} / \mathrm{O}$ contact was present in $35 \%$ of patients.

Van Beers et al. have shown that risk of a person developing leprosy is four times higher when there is a neighbourhood contact and up to nine times higher when the contact is intra familial. Further, the risk is higher if contact has MB form of the disease. Thus, it is important to take detailed contact history and screening of family members whenever possible. ${ }^{[10]}$

\section{WHO classification:}

In our study, 10 (40\%) patients were Paucibacillary, 15 (60\%) patients were Multibacillary. In Singal et al study, $48.3 \%$ patients are paucibacillary, $51.7 \%$ patients are multibacillary. In Sachdeva et al study, $74 \%$ patients are paucibacillary, $26 \%$ patients are multibacillary.

High incidence of Multibacillary cases is in contrast to most previous studies and is most likely due to the use of a different set of criteria for disease classification by previous workers such as the 1988 WHO classification, where they included the number of lesions as a criteria without considering the number of Involved nerves as a differentiating factor. In our series too, a significant number of patients with BT leprosy were qualified as MB disease due to more than one nerve trunk involvement.

\section{AFB status:}

In our study, slit skin smear was positive in $20 \%$ patients.

Singal et al found smear positivity in $19.8 \%$ patients, which was in concordance with our study.

Chaitra et al found smear positivity in $8.33 \%$ patients, which was less compared to our study.

The risk of disease transmission to contacts was higher with AFB + Ve patients than AFB -Ve patients.

\section{Clinical types of leprosy:}

In our study, most common type was 13 patients of Borderline Tuberculoid leprosy (BT) (52\%), followed by 8 patients of Tuberculoid leprosy(TT) (32\%), 3 patients of Borderline lepromatous leprosy (BL) $(12 \%)$ and one patient of Lepromatous leprosy(LL) (4\%). Clinically, no patient of mid borderline leprosy, histoid leprosy and pure neuritic leprosy was detected. 
According to Singal et al, Borderline tuberculoid leprosy was the commonest clinical type (70.3\%) followed by Tuberculoid leprosy (5.8\%), mid-borderline leprosy (BB) (1.2\%), borderline lepromatous leprosy (BL) $(9.9 \%)$, lepromatous leprosy (LL) $(4.1 \%)$, pure neural leprosy (PNL) $(4.6 \%)$ and indeterminate leprosy $(4.1 \%){ }^{[7]}$

According to Chaitra et al, Tuberculoid leprosy (TT) was the commonest clinical type (50\%) followed by borderline tuberculoid $(38.89 \%)$, indeterminate $(5.56 \%)$, and borderline lepromatous $(2.78 \%)$ types. No patient of childhood pure neural leprosy was registered during their study period. Histoid type was seen in a 14 -year-old boy $(2.78 \%){ }^{[8]}$

\section{Histological types of leprosy:}

Borderline tuberculoid (48\%) was the common type according to histological features, followed by tuberculoid leprosy $(36 \%)$, indeterminate leprosy $(8 \%)$, borderline lepromatous leprosy $(4 \%)$, lepromatous leprosy $(4 \%)$.

\section{Clinico- Histopathological correlation:}

In our study clinico histopathological correlation was seen in $72 \%$.

Singal et al study showed $86.1 \%$ and Chaitra et al showed $85.16 \%$ clinic histopathological correlation.

The selection of optimum lesion for biopsy might have been responsible for the high percentage of correlation.

\section{Reactions:}

Incidence of reactions is seen in 2 patients (8\%) according to our study. All of them were Type 1 reaction. Singal et al found reactions in $18.6 \%$ of childhood leprosy patients.

Chaitra et al found reactions in $5.56 \%$ patients.

Incidence of reactions in our study was less than Singal et al studies but higher than Chaitra et al studies. This may be because majority of our patients were in Tuberculoid spectrum and Type 1 reaction is common in this spectrum.

\section{Deformities:}

Incidence of deformities was $8 \%$ according to our study.

Singal et al found deformities in $12.8 \%$ of childhood leprosy patients.

Chaitra et al found deformities in $13.89 \%$ patients.

The less incidence of deformities in our study may be due to early detection of childhood patients.

Occurrence of deformities is associated with the following factors: increasing age, high bacillary load, multiple nerve thickening and presence of reaction at the time of presentation (Singal et al).

\section{HIV and Leprosy:}

In our study one patient of lepromatous leprosy had coinfection of HIV, with BI 5+. This patient presented with multiple $(>20)$ skin lesions, multiple nerve involvement along with claw hand, banana fingers and trophic ulcers. Predominance of the multi bacillary (MB) leprosy and a faster clinical evolution of the leprosy was observed in HIV patients, because of reduced cell mediated immunity. ${ }^{[11]}$

\section{Conclusion}

Despite statistical elimination of leprosy, childhood leprosy remains a public health problem and bears a significant social impact. Early detection, treatment and contact tracing are important for reducing the burden of childhood leprosy in the community. Though a lot has been achieved at national level, much need to be done in pockets of high prevalence in terms of case detection, patient education and counselling, in addition to MDT coverage.

Because of broad clinical spectrum of disease, patients may present with different morphological varieties, so it is quite difficult in making a diagnosis by the treating physician, where SSS and histopathological examination may help in confirmation of diagnosis.

As our study is based on data obtained from outpatient department of a tertiary hospital it may not represent the actual problem in the society. So there is need for house to house epidemiological survey to detect hidden cases of childhood leprosy.

\section{References}

[1]. World Health Organisation. Global leprosy: update on the 2012 situation. Weekly epidemiol rec 2013:88:365-380

[2]. NLEP- Progress report for the year 2011-2012 ending on 31st March 2012.

[3]. Journal of public health and epidemiology vol. 2(9), pp. 267-271, December 2010. Sandeep sachdevan et al

[4]. Jopling WH, McDougall AC. The disease. 5th ed. New Delhi: CBS Publishers and Distributors; 1996. pp. 10-53.

[5]. World Health Organisation. Global leprosy situation, 2009. Weekly Epidemiological Record, No. 33, 2009; 84:333-340.

[6]. Aparna Palit, Arun C. Inamadar, Childhood leprosy in India over the past two decades. Lepr Rev(2014)85,93-99. 
[7]. Singal A. Sonthalia S. Pandhi D. Childhood leprosy in a tertiary-care hospital in Delhi. India: a reappraisal in the post-elimination era. Leprosy Review. 2011:82(3):259-269.

[8]. Chaitra P. Bhat RM. Postelimination status of childhood leprosy: report from a teritiary-care hospital in South India. Biomed Res Int. 2013;2013:328673- 328673.[PubMed].

[9]. Hastings RC, Opromalla DVA. Leprosy, 2nd edn. Edinburgh, Churchill Livingstone, 1994.

[10]. Van Beers SM, Hatta M, Klatser PR. Patient contact is the major determinant in incident leprosy: Implications for future control. Int J Lepr Other Mycobact Dis 1999;67(2):119-28.

[11]. Gebre S, Saunderson P, Messele T et al. The effect of HIV status on the clinical picture of leprosy: a prospective study in Ethiopia. Lepr Rev 2000; 71: 338-43.

Dr.T.V. Narsimha Rao. "A Clinico Histopathological Study of Childhood Leprosy ." IOSR Journal of Dental and Medical Sciences (IOSR-JDMS) 16.7 (2017): 83-90. Web. 